\title{
Information Security in Civil Aviation
}

\author{
G.D.Zhangissina, Karimov T.A., Kim P.A., Kim M.V., Kazakhstan, Almaty \\ Vice-Prezident of International Academy of Informatization, \\ Kazakhstan, Almaty \\ gul_zhd@mail.ru
}

\begin{abstract}
In this paper is considered Information Security in Civil Aviation. This is the more important topic. Because the Security of country dependens from Information Security in Civil Aviation.

Key words: information security, civil aviation, information, security, protection, transport, information, system, antivirus, range, company.

There are many definitions of information security (IB), for example:

- Information security is the process of ensuring the confidentiality, integrity and availability of information.

- information security - all aspects related to the definition, achievement and maintenance of confidentiality, integrity, availability, accountability, authenticity and reliability of information or means of its processing.

- information security is determined by the absence of unacceptable risk associated with information leakage through technical channels, unauthorized and unintended effects on data and (or) on other resources of an automated information system used in an automated system.

All definitions mean about the same thing: for example, you have a customer base, you want to be sure that only you have access to it, and at any time the information will be correct there. For example, the names and phone numbers of customers will be the same as what you entered there, and no one changed them. For this and need to protect the database.

The relevance of information security in the informatization of society. The relevance of information security is due to the ever-increasing informatization of society. The scope of application of computer technology is constantly increasing (telephones, finance, technological process management at enterprises, etc.), the amount of data processed in information systems is also increasing, and geographically distributed computing systems are also becoming increasingly common.

The more information is concentrated in the information system, the more willing to get it, and the more complex the system itself - the more potential vulnerabilities it has. But to abandon the use of information systems for solving various tasks is no longer possible, and it remains either to put up with the possibility of leaking important data, or to protect them.

Moreover, it is necessary to protect the information values accordingly, for example, antivirus, firewall should be installed on a personal computer and vigilance should be exercised when surfing the Internet (especially important when using online banking), and to ensure data protection in a company, you may need a whole range of measures and serious technical tools. protection.
\end{abstract}


Information security in civil aviation.

If we consider the relevance of information security for civil aviation, it is worth starting with the definition of information that requires protection. This may be information, the value of which we define ourselves, or information that has legally determined value.

1. Protection of information of value to the company:

- commercial secrets - a wide range of information; companies themselves refer certain data to commercial secrets, various financial information, marketing plans, customer bases, contact information of foreign partners, etc.

- building plans are information that may be physically damaged by the leakage; the same terrorist attack is preceded by gathering information, finding out the building plans, how cameras are placed in them, possibly a schedule and a plan for going around the premises.

- placement of cameras. Information to be protected by laws.

How to ensure information security in airlines?

Information security in the field of civil aviation is achieved by the timely adoption of a number of measures and certain means of protection in airlines, airports and in companies-counterparties.

1. Organizational measures. First of all, the protection of information should begin with a person, with an employee who will assume the responsibility to ensure information security in the company. If the company is very large, then one employee can not do, and it is better to create a department of at least 3 people, one manager and two engineers. In any case, the employee or the head of the department must have a good understanding of information security issues, the level of competence of the employee will necessarily affect the financial costs of information security. When an employee is found, after studying the information processes in the company, he must develop appropriate organizational and administrative documents, which are signed by the main person in the company.

2. Physical measures - restriction of physical access to the protected information.

3. Technical measures - various means of protecting against unauthorized access, protection of information from leakage through technical communication channels, cryptographic means of protecting information, systems for protecting against DDOS attacks. 